\title{
College Women's Feminist Identity: A Multidimensional Analysis with Implications for Coping with Sexism
}

\author{
Campbell Leaper • Diana M. Arias
}

Published online: 8 February 2011

(C) The Author(s) 2011. This article is published with open access at Springerlink.com

\begin{abstract}
This study examined components of women's feminist identity and possible relations to their reported coping responses to sexism. A sample of 169 undergraduate women $(M=19.4 \mathrm{y}, S D=1.2)$ from diverse ethnic backgrounds completed surveys assessing their experiences and gender-related views. The first set of analyses revealed that women's social gender identity, exposure to feminism, and gender-egalitarian attitudes independently contributed to feminist identification; moreover, non-stereotyping of feminists further predicted feminist self-identification. A second set of analyses tested the relative contribution of feminist identity components to women's cognitive appraisals of coping responses to sexual harassment. Seeking social support was predicted by self-identification as a feminist (for White European American women only). Confronting was predicted by social gender identity, nonstereotyping of feminists, and public identification as a feminist. Findings highlight possible components of women's feminist identity and their possible impact on coping responses to sexism.
\end{abstract}

Keywords Sexism $\cdot$ Discrimination $\cdot$ Feminism $\cdot$ Identity Sex role attitudes $\cdot$ Coping $\cdot$ Sexual harassment

\section{Introduction}

Feminism refers to a belief in gender equality and an awareness of contemporary gender discrimination at inter-

C. Leaper $(\bowtie) \cdot$ D. M. Arias

Department of Psychology, University of California, Santa Cruz, Room 277 Social Sciences II, 1156 High Street,

Santa Cruz, CA 95064-1077, USA

e-mail: cam@ucsc.edu personal and societal levels (e.g., Jackson et al. 1996). Paradoxically, many women who endorse gender equality do not identify as feminists. Identifying as a feminist may have its benefits, however, because feminism may empower women to challenge sexism in their lives and the larger society. The present study examined women's feminist identity in two ways. First, we considered multiple components that may contribute to women's self-identification as a feminist. Second, we explored which of these components might be related to women's proactive coping responses to sexist events.

\section{Identification as a Feminist}

The first aim of our study was to consider the multi-faceted aspects of a feminist social identity within a single study. According to one model, feminist identity emerges in a series of stages ranging from becoming aware of sexism to getting involved in collective action (e.g., Downing and Roush 1985). An alternative approach, which we adopted in the present study, is to consider the components or dimensions that underlie feminist identity (e.g., see Hyde 2002; Liss and Erchull 2010; Moradi et al. 2002). In an analogous manner, researchers have developed multidimensional models of gender identity (e.g., Egan and Perry 2001; Spence 1993).

Our conceptualization of feminist identity is primarily guided by social identity (or intergroup) theory, which emphasizes the impact of group belonging on one's attitudes and behavior (Deaux et al. 1999; Tajfel 1982; Turner 2000). The theory addresses the ways that identifying with a group can affect individuals' thinking and behavior. When a woman identifies as a feminist, she is aligning herself with other individuals who are also feminists. 
Our multidimensional model of feminist identity includes three components: women's gender-related experiences (sexist events and exposure to feminism), gender-related cognitions (social gender identity, gender-egalitarian attitudes, and awareness of sexism), and stereotypes regarding feminists. In addition, we took into account the potential relevance of women's sociocultural backgrounds (ethnicity and SES). Whereas prior studies (described below) have tested the correlations between feminist self-identification and each of these factors, their relative influences have not been examined in a single investigation. Below, we review the relevance of each component. First, we address the reasons for considering sociocultural background in the model.

\section{Sociocultural Background}

According to intersectional approaches (Cole 2009), it is important to consider the interrelationship among different social status variables. Accordingly, we took into account participants' socioeconomic and ethnic backgrounds when testing predictors of feminist identity. It is important to consider both factors because they can be confounded, with a disproportionate number of ethnic minorities represented at lower economic levels (U. S. Census Bureau 2008).

Socioeconomic background The education level of participants' parents is an approximate index of socioeconomic status commonly used in studies (e.g., Ex and Janssens 1998; Finkelstein et al. 2007). Some research suggests that feminist beliefs (Morgan 1996) and gender-egalitarian attitudes (Ex and Janssens 1998) are more likely among women whose mothers had higher education levels. Women from higher-SES families may have more opportunities to learn about feminism. Furthermore, individuals from higher-SES (vs. lower-SES) backgrounds are more likely to have psychosocial resources that help them cope with stressors (Finkelstein et al. 2007), such as sexism.

Ethnic background Prior research suggests possible differences between ethnic-minority women and White European American women in the formation of a feminist identity (e.g., Harnois 2005; Henley et al. 1998). Besides controlling for ethnic-minority background when testing other predictors of feminist identification, we additionally examined if ethnic-minority status moderated any of the components in our model. The relation between ethnic background and feminist identification is potentially complicated. On the one hand, there are some factors that might lead ethnic-minority women to be more likely to identify as feminists. Experiences with race- and ethnic-based discrimination may sensitize ethnic minorities or persons of color to all forms of discrimination (e.g., Klonoff et al. 1995; Reid and Comas-Diaz 1990). Thus, women from ethnic- minority backgrounds may have a greater awareness of sexism than do White European American women. This might increase the likelihood of feminist identification. On the other hand, there are other reasons why feminist identification may be more common among White European American women. Many ethnic-minority women may be reluctant to identify as feminists because they view it as a movement primarily for White middle-class women (Aronson 2003; Harnois 2005; Myaskovsky and Wittig 1997). Furthermore, on average, race and ethnicity may be more central to the identities of ethnic-minority women than to White European American women (Levin et al. 2002; Turner and Brown 2007). Consequently, it may follow that gender and sexism tend to be more salient to White European American women than ethnic-minority women. However, it is also possible that identifying as a feminist involves a similar set of components for women regardless of their ethnic identity. Thus, we tested if ethnic background moderated any effects, but we did not necessarily expect any significant interactions.

\section{Gender-Related Experiences}

Sexist events and exposure to feminism are two kinds of experience that we hypothesized would increase women's likelihood of identifying as feminists.

Sexist events Surveys indicate that the vast majority of adolescent girls and young women have experienced sexual harassment (American Association of University of Women 2001; also see Leaper and Robnett 2011, for a review). A woman who is subjected to sexism may find that becoming a feminist is a way to empower herself against future discrimination (e.g., Jackson et al. 1996; Jagger 1983). Indeed, prior reports indicate that women who identify as feminists are more likely than other women to report gender discrimination (Ayres et al. 2009; Buschman and Lenart 1996; Cowan et al. 1992; Fischer et al. 2000; Zucker 2004). We hypothesized that women's experience with sexual harassment would be positively related to feminist selfidentification.

Exposure to feminism To identify with any group, a person must become familiar with its existence and defining features. During development, girls and women may learn about gender discrimination and feminism from family members and friends, in school, and through the media (Leaper, and Brown 2008). Besides informing women about gender discrimination, these sources may help dispel myths about feminism (e.g., "Feminists hate men"). The positive impact of exposure to feminism on women's feminist identity has been indicated in a few reports (Henderson-King and Stewart 1999; Myaskovsky and Wittig 1997; Reid and 
Purcell 2004; Williams and Wittig 1997; Zucker 2004). Exposure to feminism is also related to women's support of feminist goals and values (Bargad and Hyde 1991; Williams and Wittig 1997). Thus, we hypothesized the exposure to feminism would be positively related to feminist self-identification.

\section{Gender-Related Cognitions}

Gender-related cognitions include the self-concepts and attitudes that define what it means to be a feminist. In particular, we considered the possible relations of social gender identity, gender-egalitarian attitudes, and awareness of sexism in society to women's likelihood of identifying as feminists.

Social gender identity Social gender identity refers to the importance that one places on one's gender ingroup. Previous studies indicate that women's social gender identity predicts their self-identification as feminists and feminist ideology (Burn et al. 2000; Henderson-King and Stewart 1997; Liss et al. 2001; Smith 1999). Given that the feminist movement's goal is to improve women's status, a sense of solidarity with other women may help women recognize that women are generally subjected to discrimination based on their gender. In this regard, having a strong social identity as a woman may be a necessary (but not sufficient) component of feminist identity.

Gender-egalitarian attitudes Groups are typically defined by a set of norms and values (Deaux et al. 1999; Tajfel 1982; Turner 2000). Support of gender equality is a cardinal belief associated with liberal and radical feminism (Henley et al. 1998). Indeed, several studies have found a positive correlation between self-identification as a feminist and gender-egalitarian attitudes (Cowan et al. 1992; Henderson-King and Stewart 1994; Jackson et al. 1996; Liss and Erchull 2010; Morgan 1996; Myaskovsky and Wittig 1997; Nelson et al. 2008; Reid and Purcell 2004). Following this prior work, we expected that genderegalitarian attitudes would be positively associated with feminist self-identification.

Awareness of sexism Another cognitive component of feminist identity may include recognizing that institutionalized sexism occurs in society. Awareness of sexism and endorsing gender equality are not necessarily the same. The construct of modern sexism is premised on this notion (Swim et al. 1995). That is, some people profess equal rights for women and men while also expressing the view that gender discrimination in society is no longer a problem. Also, studies have demonstrated that awareness of sexism in society is more likely among women who identify as feminists (Downing and Roush 1985; Henderson-King and Stewart 1994; Henderson-King and Zhermer 2003; Morgan 1996; Myaskovsky and Wittig 1997; Szymanski 2004; Williams and Wittig 1997; Zucker 2004). Because gender-egalitarian attitudes and awareness of societal sexism are fundamental to being a feminist, we predicted that these beliefs would independently contribute to women's identification as feminists.

\section{Stereotyped Evaluations of Feminists}

Women's stereotyped evaluation of feminists constitutes the fourth component in our multidimensional model of feminist identity. Adopting a social identity is associated with having a positive evaluation of the ingroup (Deaux et al. 1999; Tajfel 1982; Turner 2000). Internalizing negative stereotypes about feminists may be an impediment against adopting a feminist identity for many women. Feminists are regularly demonized in the popular media (see Anderson 2010, for a review). For example, consider the title of conservative writer Kate O'Beirne's (2006) book: Women who make the world worse and how their radical feminist assault is ruining our schools, families, military, and sports. In an interview, O'Beirne opined, "I have long thought that if high-school boys had invited homely girls to the prom we might have been spared the feminist movement" (Lopez 2005). Rush Limbaugh, another conservative commentator, similarly asserted that "feminism was established to allow unattractive women easier access to the mainstream" (Limbaugh 2005, August 12).

Negative stereotyping about feminism may lead many women to form misconceptions about what it means to be a feminist (e.g., Houvouras and Carter 2008; Manago et al. 2009). Indeed, prior studies found that women were more likely to identify as feminists if they held non-stereotypical views of feminists (Cowan et al. 1992; Henderson-King and Stewart 1994; Liss et al. 2001; Myaskovsky and Wittig 1997; Reid and Purcell 2004; Roy et al. 2007; Rudman and Fairchild 2007; Williams and Wittig 1997; Zucker 2004). Thus, we hypothesized that stereotyping feminists would predict feminist self-identification even after controlling for other components. Compared to earlier studies, our analysis was relatively unique in testing the predictive value of stereotyping feminists on women's feminist identification after controlling for factors such as social gender identity and egalitarian attitudes.

Facets of Feminist Identity: Implications for Coping with Sexism

In the second part of our study, we tested how the different facets of feminist identity might be related to women's coping 
responses to sexism. Although many women support gender equality, those who identify as feminists may have a greater commitment to eradicating oppression toward women (Zucker 2004). Therefore, we expected self-identified feminists would be more likely than other women to endorse proactive coping strategies in response to sexism.

We focused on women's cognitive appraisals of different responses to hypothetical experiences with sexual harassment. According to Lazarus and Folkman's (1984) stress and coping model, cognitive appraisals of stressful situations are related to individuals' actual coping strategies (also see Lazarus 1999). That is, the individual evaluates the situation and decides how to respond. Additional research has highlighted the relevance of this model to women's coping with sexism (e.g., Ayres et al. 2009; Cortina and Wasti 2005; Foster 2000; Kaiser and Miller 2004). In general, researchers have found that proactive (or engagement) strategies, such as confronting or seeking support, are more effective than avoidant (or disengagement) strategies in reducing the negative effects commonly associated with stress in general (Lazarus 1999) and sexism in particular (Foster 2000).

The two proactive coping strategies that we investigated are confronting and seeking social support. A direct way of dealing with a sexist event is to confront the perpetrator. Confronting is a problem-focused coping strategy whereby the source of the stress is directly addressed. Deciding to confront a perpetrator begins with a cognitive appraisal of the relative interpersonal benefits (e.g., reducing recurrence) and costs (e.g., retribution) of taking this action (Dodd et al. 2001; Kaiser and Miller 2004; Swim and Hyers 1999).

There are some situations when confrontation may not be an appropriate response to sexual harassment, such as when the perpetrator poses a threat to the woman's physical or psychological safety (Kaiser and Miller 2004; Shelton and Stewart 2004). Hence, a complementary proactive strategy is to seek social support after a sexist event. For example, a woman may ask others for practical advice or she may seek emotional reassurance. Previous research has noted the potential importance of social support in relation to women's coping with sexism (Foster 2000).

\section{Predictors of Reported Coping}

As reviewed below, we hypothesized that components of women's feminist identification would predict their cognitive appraisals of confronting and seeking support in response to sexist events. These components included (a) gender-related experiences, (b) gender-related cognitions, and (c) stereotypes of feminists and feminist identification. As was performed in the first set of analyses testing predictors of feminist identification, we also controlled for socioeconomic and ethnic backgrounds. Furthermore, we tested if ethnicminority status moderated any of the associations.

Gender-related experiences Exposure to feminism and experiences with sexism are two gender-related experiences that we considered as possible influences on women's coping with sexism. Being exposed to feminism may help women to recognize that sexist events are wrong and thereby empower them to confront the incidents or to seek help. Experiences with sexism, however, might have either a positive or negative impact of proactive coping. On the one hand, having experienced more sexism (or at least acknowledging such experiences) may lead women to deal more actively with it (e.g., Foster 2000; Nelson et al. 2008). On the other hand, repeated experiences with sexism can have debilitating effects on women's adjustment (Moradi and Subich 2002) and thereby diminish their coping resources.

Gender-related cognitions According to cognitive consistency theory (McGuire 2000), confronting sexism should be consistent with a belief in gender equality and an awareness of sexism. That is, if a woman positively appraises confronting or reporting sexism, presumably she believes sexism is immoral. Prior research suggests that increasing women's awareness of sexual harassment leads to higher rates for reporting incidents to authorities (Jaschik-Herman and Fisk 1995). Therefore, women with egalitarian attitudes and awareness of sexism may be more likely than other women to view gender discrimination as inappropriate behavior that should be challenged. Furthermore, to the extent that women feel a sense of solidarity with other women (i.e., social gender identity), they may feel like it is their obligation to act to support their ingroup.

Stereotyped evaluations of feminists and feminist selfidentification Our primary research question when testing predictors of coping appraisals was whether stereotyping of feminists and feminist identification were significant after controlling for other variables. That is, we wanted to examine whether positively viewing feminists and having a feminist identity might benefit women when coping with sexism. In support of this proposal, previous research has found that feminist identity is associated with overall selfefficacy (Eisele and Stake 2008); the latter characteristic is generally related to adaptive coping (Park and Folkman 1997).

According to our multidimensional model, having nonstereotypical views of feminists is an independent facet of becoming a feminist. We therefore speculated that women who have non-stereotypical views of feminists and identify as a feminist themselves would be most likely to endorse proactive responses to sexism. Conversely, women who 
hold stereotyped views of feminists or do not identify as feminists may hesitate to confront or tell others about sexist events because they do not wish to appear radical.

To our knowledge, only one previous study has investigated women's self-identification as a feminist in relation to their coping with sexist events. Ayres et al. (2009) found that women who identified as feminists were more likely to report having used confrontation or social support in a personal narrative about an experience with sexism. Other studies have found that feminist identity is related to women's commitment to collective action (e.g., Downing and Roush 1985; Liss et al. 2004; Nelson et al. 2008), which is a proactive response to sexism (but not necessarily a coping response to a specific sexist event). To build on this prior work, we hypothesized that women's feminist identity would predict their endorsement of proactive coping strategies - specifically seeking support and confronting - after controlling for other relevant factors.

When testing feminist identity as a predictor of coping, we distinguished between women's private and public selfidentification as a feminist (Szymanski 2004; Zucker 2004). Zucker (2004) reasoned that public self-identification as a feminist reflects a stronger commitment to the goals of feminism than does private self-identification (also see Downing and Roush 1985; Hyde 2002; Moradi and Subich 2002). As theory and research on identity development has emphasized, individuals may go through an exploration phase before making a commitment to particular selfdefinitions (e.g., Marcia 1980). Thus, some women may begin to privately embrace a feminist identity while hesitating to share that possibility with others (i.e., private self-identification). Upon committing to the identity, they may share this aspect of the self to others (i.e., public selfidentification). Whereas both public and private selfidentification as a feminist might be correlated with proactive coping responses to sexism, a woman who openly expresses her feminist identity may find it more consistent with her self-concept and attitudes either to tell others about the sexist event or to confront the perpetrator. Hence, public self-identification may be a stronger predictor of proactive coping.

\section{The Present Study}

Our study had two related research goals. First, we tested a multidimensional model of feminist identity that distinguished among different facets. Each of the main predictors in our model has been previously shown to correlate with women's self-identification as feminists. What has been missing, however, is an examination of the relative associations of these factors in the same study. The second part of our study explored if and how the facets of feminist identity predict women's coping responses to sexism. There have been no prior studies examining the relative influences of these factors in relation to women's reported coping.

\section{Method}

\section{Participants}

The sample consisted of 169 college women $(M=$ 19.39 years, $S D=1.20$, range $=18-22$ ) who were required to participate in research as a psychology course requirement. Participants' ethnic backgrounds were 54\% White European American, 14\% Asian, 10\% Latina, 3\% Pacific Islander, 2\% Middle Eastern, 2\% African American, 1\% East Indian, and 14\% mixed-ethnicity participants; also, 1 participant did not report ethnicity. With regards to selfidentified sexual orientation, 160 identified as heterosexual, 2 as bisexual, 1 as lesbian, 3 as other, and 3 who did not respond to the question. The highest education level of the participants' parents were as follows: $11.8 \%$ of mothers and $10 \%$ of fathers had no more than a high school education; $19.5 \%$ of mothers and $29 \%$ of fathers had some college (without a bachelor's degree); $27.8 \%$ of mothers and 34.9\% of fathers had a bachelor's degree; and $31.9 \%$ of mothers and $22.5 \%$ of fathers had attended some graduate school or received an advanced degree; the median for both mothers and fathers was some college.

\section{Procedure}

Women were recruited through a university research pool of students from psychology classes. They took an online survey that was described as a study of women's identity and attitudes. Participants could terminate their participation at any point and could not return to the survey responses at a later point in time. A debriefing statement appeared onscreen after completion of the questionnaire.

\section{Measures}

Unless otherwise indicated, survey items were rated using a 6-point scale ( $1=$ strongly disagree to $6=$ strongly agree). Mean ratings, standard deviations, and (when appropriate) alpha coefficients of internal reliability for the measures are presented in Table 1.

\section{Parents’ Education}

Parents' education level was used as an index of socioeconomic status (e.g., see Ex and Janssens 1998; Finkelstein et al. 2007). Participants separately indicated their mother's 
Table 1 Means, standard deviations, alpha coefficients, and bivariate Spearman correlations $(N=169)$

\begin{tabular}{|c|c|c|c|c|c|c|c|c|c|c|c|c|}
\hline Measure & 1 & 2 & 3 & 4 & 5 & 6 & 7 & 8 & 9 & 10 & 11 & 12 \\
\hline 1. Ethnic status & - & & & & & & & & & & & \\
\hline 2. Parent education & $-.18^{*}$ & - & & & & & & & & & & \\
\hline 3. Sexist events & -.03 & .07 & - & & & & & & & & & \\
\hline 4. Feminism exposure & -.11 & $.23^{* *}$ & $.32^{* * *}$ & - & & & & & & & & \\
\hline 5. Social gender identity & .10 & -.06 & $.23^{* *}$ & $.24^{* *}$ & - & & & & & & & \\
\hline 6. Egalitarian attitudes & -.07 & $.15^{*}$ & $.24^{* *}$ & $.35^{* * *}$ & .14 & - & & & & & & \\
\hline 7. Sexism awareness & -.10 & .06 & $.52^{* * *}$ & $.31^{* * *}$ & $.40^{* * *}$ & $.41^{* * *}$ & - & & & & & \\
\hline 8. Feminist stereotyping & $.20^{* *}$ & -.13 & $-.20^{*}$ & $-.32^{* * *}$ & $-.24^{* *}$ & $-.39^{* * *}$ & $-.35^{* * *}$ & - & & & & \\
\hline 9. Private feminist & -.14 & .00 & $.34^{* * *}$ & $.47^{* * *}$ & $.34^{* * *}$ & $.46^{* * *}$ & $.40^{* * * *}$ & $-.56^{* * *}$ & - & & & \\
\hline 10. Public feminist & -.02 & -.06 & $.24^{* *}$ & $.44^{* * *}$ & $.31^{* * *}$ & $.32^{* * *}$ & $.25^{* *}$ & $.50^{* * *}$ & $.71^{* * *}$ & - & & \\
\hline 11. Seek support & $.18^{*}$ & .11 & .10 & .13 & $.21^{* *}$ & $.24^{* *}$ & $.23^{* *}$ & -.05 & .10 & .04 & - & \\
\hline 12. Confront sexism & .03 & -.06 & .03 & .10 & $.30^{* * *}$ & .05 & $.19^{*}$ & $-.25^{* *}$ & $.24^{* *}$ & $.36^{* * *}$ & -.01 & - \\
\hline$M$ & $\mathrm{n} / \mathrm{a}$ & 4.83 & 4.78 & 5.01 & 4.53 & 4.84 & 4.85 & 3.00 & 3.72 & 2.78 & 4.75 & 3.31 \\
\hline$S D$ & $\mathrm{n} / \mathrm{a}$ & 1.32 & 1.11 & 1.93 & 1.07 & .69 & .86 & .54 & 1.63 & 1.56 & 1.24 & .76 \\
\hline Range & $\mathrm{n} / \mathrm{a}$ & $1-7$ & $1-6$ & $1-8$ & $1-6$ & $1-6$ & $1-6$ & $1-5$ & $1-6$ & $1-6$ & $1-6$ & $1-6$ \\
\hline$\alpha$ & $\mathrm{n} / \mathrm{a}$ & .71 & .74 & $\mathrm{n} / \mathrm{a}$ & .80 & .72 & .83 & .74 & $\mathrm{n} / \mathrm{a}$ & $\mathrm{n} / \mathrm{a}$ & .79 & .68 \\
\hline
\end{tabular}

$\mathrm{n} / \mathrm{a}=$ not applicable. Ethnic status was dummy coded $(0=$ White European American, $1=$ ethnic minority or mixed ethnicity $)$. Alpha coefficients of scale reliability are reported for the above measures when appropriate. Exceptions include ethnic status (dichotomous variable), feminism exposure (frequency count), private feminist identity (single item), and public feminist identity (single item). To make it easier to interpret the rating scales, the average rating across items for each scale was used

${ }^{*} p<.05 .{ }^{* *} p<.01 .{ }^{* * *} p<.001$

and father's highest level of education as follows: $1=$ elementary school, $2=$ some high school, $3=$ high school graduate, 4=some college, $5=$ bachelor's degree, $6=$ some graduate school, or $7=$ graduate degree (master's, doctorate, medical, law, etc.). For later analyses, we used the average of the mother's and the father's education levels.

\section{Feminist Self-Identification}

Two items were used to measure women's degree of feminist self-identification (Szymanski 2004). One item assessed private self-labeling as a feminist ("I consider myself a feminist") and another item measured public self-labeling as a feminist ("I identify myself as a feminist to other people").

\section{Personal Experiences with Sexual Harassment}

Items from the Schedule of Sexist Events pertaining to sexual harassment (Klonoff and Landrine 1995) were used to assess personal experiences with sexism. Participants rated their experiences with three kinds of sexual harassment ("Called you a nasty or demeaning name related to being a woman," "Told an embarrassing/mean joke about girls/women in your presence," "Received inappropriate or unwanted romantic attention"). Higher scores reflect greater endorsement of having experienced sexual harassment.

\section{Exposure to Feminism}

Reid and Purcell's (2004) survey items for assessing exposure to feminism were adapted for use in the present study. The directions read as follows: "We just asked you about your impression of feminists. As defined in the dictionary, feminism refers to the belief in equality for women and men. Many feminists point to ways that society and certain individuals discriminate against women in ways that hassle them or limit their opportunities. When this occurs, it is known as sexism" (original emphasis). Respondents were subsequently asked if they had learned about feminism from the media, a women's studies course, their mother or anyone else in their family, their teachers or coaches, or their friends or classmates. In addition, they were asked if any of the following considered themselves feminists: their mother or other family member, their high school friends or classmates, or their current college friends. For each of these 8 items, the response options were either no (0) or yes (1). The scores were summed to create an index of exposure to feminism.

\section{Social Gender Identity}

Social gender identity was measured using the 4-item Identity subscale of Luhtanen and Crocker's (1992) Collective Self-Esteem Scale. For the present study, the 
Identity subscale was used to assess the perceived importance of the respondent's social identity as a woman (e.g., "Being a woman is an important reflection of who I am"). The measure had 2 reverse coded items. Higher scores reflected a stronger social gender identity.

\section{Gender-Egalitarian Attitudes}

Attitudes toward egalitarian versus traditional gender roles were measured using items from two prior gender attitude scales (Galambos et al. 1985; Morgan 1996). Participants were asked to rate their agreement to 9 statements regarding the relative roles and responsibilities for girls/women and boys/men (e.g., "A woman should not let pregnancy and child-rearing stand in the way of a career if she wants it"). The scale included 4 items with higher scores (after reverse scoring) indicating greater gender-egalitarian attitudes.

\section{Awareness of Sexism in Society}

The Contemporary Gender Discrimination scale (Rosell and Hartman 2004) was used; it consists of 7 items measuring a belief in current societal gender discrimination (e.g., "Although it is more subtle than it used to be, women still experience discrimination"). Higher scores indicate greater awareness in contemporary gender discrimination.

\section{Stereotyped Evaluations of Feminists}

Attitudes toward feminists were assessed using Reid and Purcell's scale (2004; which was adapted from BerrymanFink and Verderber 1985). The directions were as follows: "People have different views about what it means to be a feminist.... Rate the average feminist on the following qualities...." There were 9 paired items: desirable/undesirable, beautiful/ugly, sexy/plain, feminine/masculine, sexual/ frigid, straight/gay, traditional/radical, likes men/hates men and very concerned with appearance/not concerned with appearance. These were rated on a 5-point scale (e.g., $1=$ beautiful to $5=u g l y$ ). Three items were dropped (not concerned with appearance, radical, and masculine) to improve the internal reliability of the scale. Higher scores reflect more stereotyped views of feminists.

\section{Coping Responses to Sexism}

Two scales were devised for the present study to assess participants' cognitive appraisals of two coping strategies following sexual harassment.

Seeking social support Two items adapted from Lazarus and Folkman (1984) assessed participants' cognitive appraisal of seeking social support after experiencing sexual harassment ("If someone sexually harassed me, I would probably talk to someone about how I was feeling" and "If someone sexually harassed me, I would probably talk to someone else who could do something specific about the problem").

Confronting Participants' cognitive appraisal of the perceived benefits of confronting sexism was assessed using items adapted from Kaiser and Miller (2004). Participants were asked to imagine that they confronted a person for sexual harassment ("told someone to stop behaving in a harassing way"), and then were asked to appraise the potential benefits of confronting the harasser on three items (e.g., "If I confronted someone who was acting in a sexist way, it would help reduce some of the sexism in our society").

\section{Results}

\section{Preliminary Analyses}

The means, standard deviations, and bivariate Spearman correlations among the variables are summarized in Table 1. The table provides descriptive statistics separately for women's ratings of their private and public self-identifications as feminists.

In another set of preliminary analyses, we tested for average differences based on women's ethnic-minority status $(0=$ ethnic minority/non-White, $1=$ White European American) in all of the measures. Parent education was higher for women from White European American backgrounds $(M=$ $5.08, S D=1.14)$ than ethnic-minority backgrounds $(M=4.53$, $S D=1.45), F(1,167)=12.09, p=.008, \eta^{2}=.04$. To avoid confounding parent education and ethnic-minority status, we covaried parent education in a MANCOVA testing for differences between ethnic-minority women and White European American women on the other variables. As summarized in Table 2, there was a significant multivariate effect for ethnic background. The univariate tests revealed only two significant group differences: Stereotyped evaluations of feminists were more likely among ethnic-minority women than White European American women. Also, ethnic-minority women were more likely to endorse seeking social support than were White European American women.

Feminist Identification: A Multidimensional Analysis

\section{Bivariate Correlations}

As expected, the bivariate correlations (summarized in Table 1) indicated that the following factors were related to 
Table 2 Ethnic-minority status differences in variables with parent education as a covariate

Private feminist identity and public feminist identity are dichotomous variables $(0=n o, 1=$ yes). There was a significant multivariate effect for ethnicminority status, $F(10,156)=$ $2.39, p<.001, \eta^{2}=.13$. The parent education covariate was also significant, $F(10,156)=2.40$, $p=.011, \eta^{2}=.13$

${ }^{*} p<.05 .{ }^{* *} p<.01 .{ }^{* * *} p<.001$

\begin{tabular}{lllll}
\hline Variable & $\begin{array}{l}\text { Ethnic-minority } \\
(n=77)\end{array}$ & $\begin{array}{l}\text { White European American } \\
(n=91) \\
M(S D)\end{array}$ & Univariate $F$ & $\eta^{2}$ \\
\hline Sexist events & $4.71(1.19)$ & $4.84(1.04)$ & .15 & .00 \\
Feminist exposure & $.60(.20)$ & $.65(.26)$ & .77 & .01 \\
Social gender identity & $4.67(.92)$ & $4.40(1.16)$ & 2.29 & .01 \\
Egalitarian attitudes & $4.79(.69)$ & $4.88(.69)$ & .13 & .00 \\
Sexism awareness & $4.94(.83)$ & $4.76(.87)$ & 2.48 & .02 \\
Feminist stereotyping & $3.13(.49)$ & $2.90(.56)$ & $5.98^{*}$ & .04 \\
Private feminist & $.60(.49)$ & $.65(.48)$ & .56 & .00 \\
Public feminist & $.36(.48)$ & $.32(.47)$ & .23 & .00 \\
Seek support & $4.94(1.25)$ & $4.59(1.23)$ & $4.71^{*}$ & .03 \\
Confront sexism & $3.64(.96)$ & $3.48(1.05)$ & .87 & .01 \\
\hline
\end{tabular}

women's public and private identifications as a feminist: experiences with sexist events, exposure to feminism, social gender identity, gender-egalitarian attitudes, awareness of sexism, and non-stereotyping of feminists. Neither parent education nor ethnic-minority status was related to feminist identification in the bivariate tests.

\section{Data Reduction}

For the hierarchical regression analysis testing predictors of feminist identity, private feminist identity and public feminist identity were averaged to create a single composite measure $(\alpha=.82, M=3.25, S D=1.47)$. Although private and public self-identification were strongly correlated, $r(169)=.71$, $p<.001$, women were more likely to endorse private than public identification as a feminist, $t(169)=1.08, p<.001$. In the second set of regression analyses testing predictors of seeking support and confronting, public feminist identification and public feminist identification were entered separately.

\section{Hierarchical Regression}

To test the independent contribution of different facets of women's feminist self-identification, we performed hierarchical regression analysis with the following five steps: (1) background factors (ethnic-minority status and parents' education level), (2) gender-related experiences (sexual harassment and exposure to feminism, (3) gender-related beliefs (social gender identity, gender-egalitarian attitudes, and awareness of sexism in society), (4) stereotyping of feminists, and (5) two-way interactions between ethnic status $(0=$ ethnic minority, 1=White European American) and the other variables; the last step was included to test if ethnic-minority status moderated the effects of any of the preceding factors.

The results from the regression are summarized in Table 3. The first step (background factors) was not significant. Consistent with our hypotheses, however, each of the subsequent three steps (gender-related experiences, gender-related cognitions, feminist stereotyping) significantly added to the model. Most notably, feminist stereotyping was a significant predictor in the fourth step after controlling for all of the other variables. The interaction effects in step 5 did not add to the model. Thus, the fourth step constituted the final model; it accounted for $53 \%$ of the variance.

Given that many of the predictors are correlated with one another (see Table 1), collinearity was a potential concern in the regression analyses. Accordingly, collinearity statistics were performed to assess tolerance levels. Tolerance refers to the percent of variance associated with a particular predictor that cannot be accounted for by the other predictors. Tolerance values above .10 are generally considered acceptable (Chen et al. 2003). The minimum tolerance in the final model of the regression was .71 .

The following factors were significant in the final model: mothers' education, social gender identity, exposure to feminism, egalitarian attitudes, and feminist stereotyping. As hypothesized, women were more likely to identify as a feminist if they (a) strongly identified as women, (b) had learned about feminism, (c) endorsed gender equality, and (d) held less stereotyped views of feminists.

Surprisingly, parents' education level became negatively correlated with feminist identification after life experiences were entered in the second step. In contrast, there was no association between parents' education and feminist selfidentification in the bivariate correlations (see Table 1) or the first step of the regression (see Table 3).

\section{Follow-Up Analyses}

We performed two sets of exploratory follow-up analyses. The first one explored the specific stereotypes about feminism as predictors of women's feminist selfidentification. The second set of analyses explored the 
Table 3 Standardized betas in hierarchical regression analyses for feminist self-identification

Ethnic-minority status was dummy coded $(0=$ White

European American, 1=ethnic minority or mixed ethnicity).

Two-way interactions between ethnic-minority status and the other variables were entered in the fifth step, but this step did not significantly add to the model, $F(6,154)=.37$, n.s

${ }^{*} p<.05 .{ }^{* *} p<.01 .{ }^{* * *} p<.001$

\begin{tabular}{|c|c|c|c|c|}
\hline Variable & $\begin{array}{l}\text { Model } 1 \\
\beta\end{array}$ & $\begin{array}{l}\text { Model } 2 \\
\beta\end{array}$ & $\begin{array}{l}\text { Model } 3 \\
\beta\end{array}$ & $\begin{array}{l}\text { Model } 4 \\
\beta\end{array}$ \\
\hline \multicolumn{5}{|l|}{ 1. BACKGROUND } \\
\hline Parent education & -.03 & $-.16^{*}$ & $-.17^{* *}$ & $-.17^{* *}$ \\
\hline Ethnic-minority status & -.10 & -.06 & -.09 & -.01 \\
\hline \multicolumn{5}{|c|}{ 2. GENDER-RELATED EXPERIENCES } \\
\hline Sexist events & & $.17^{*}$ & .07 & .08 \\
\hline Feminism exposure & & $48^{* * *}$ & $.34^{* * *}$ & $.28^{* * *}$ \\
\hline \multicolumn{5}{|c|}{ 3. GENDER-RELATED COGNITIONS } \\
\hline Social gender identity & & & $.23^{* *}$ & $.18^{* *}$ \\
\hline Egalitarian attitudes & & & $.28^{* * * *}$ & $.18^{* *}$ \\
\hline Sexism awareness & & & .03 & -.05 \\
\hline \multicolumn{5}{|l|}{ 4. FEMINIST STEREOTYPING } \\
\hline Feminist stereotyping & & & & $-.40^{* * *}$ \\
\hline$F_{\text {Model; }}$ & .82 & $17.24^{* * *}$ & $16.24^{* * *}$ & $22.24^{* * *}$ \\
\hline$R^{2}$ & .01 & .30 & .41 & .53 \\
\hline$F_{\text {Change }}$ & & $33.33^{* * *}$ & $1.80^{* * *}$ & $38.04^{* * *}$ \\
\hline
\end{tabular}

factors that might be related to the negative association between parents' education and feminist self-identification indicated previously in the regression.

Exploring specific feminist stereotypes in relation to feminist self-identification For exploratory purposes, we reran the above regression by substituting the composite measure of feminist stereotyping with the individual items. The purpose was to identify specific stereotypes that might particularly influence women's self-identification as feminists. Three of the stereotype items were significant: undesirable/ desirable $(\beta=-.30, p<.001)$, plain/sexy $(\beta=-.16, p<.05)$, and gay/straight $(\beta=-.18, p<.01)$. In contrast, the other stereotyped items were nonsignificant: ugly/beautiful $(\beta=.08)$, frigid/sexual $(\beta=-.03)$, hates/likes men $(\beta=-.01)$, unconcerned/very concerned with appearance $(\beta=.03)$.

\section{Exploring negative correlation between parents' education} and feminist self-identification As previously described, a negative association between feminist identity and parents' education emerged after the two gender-related experience variables were entered. In two regression analyses, we explored whether sexist events or exposure to feminism might be responsible. In both cases, we entered parents' education and ethnic-minority status in the first step. We then alternatively entered either experience with sexism or exposure to feminism. When only experience with sexism was added, parents' education remained nonsignificant $(\beta=$ $-.06, p=.40)$. But when only exposure to feminism was added, parents' education became significant $(\beta=-.15$, $p=.04)$. Thus, it appears that exposure to feminism may have a suppression effect on the relation of parents' education to feminist identification. However, because this was unexpected, it should be viewed cautiously.

\section{Coping Responses to Sexual Harassment}

\section{Bivariate Correlations}

Table 1 summarizes the bivariate correlations with the two coping responses. Seeking support was significantly and positively associated with ethnic-minority status, social gender identity, egalitarian beliefs, and sexism awareness in the bivariate correlations. Confronting was significantly and positively associated with social gender identity, sexism awareness, private feminist identification, and public feminist identification; and confronting was negatively associated with feminist stereotyping.

\section{Hierarchical Regressions}

To consider the independent contributions of the different predictor variables to coping responses, we conducted separate hierarchical regressions with seeking support and confronting. First, we tested predictors of women's reported likelihood of seeking social support in response to sexism. In a separate analysis, we tested predictors of the perceived benefits of confronting perpetrators of sexism. For each of these outcome measures, hierarchal regressions were run in five steps: (1) background (ethnic-minority status, parent education) (2) genderrelated experiences (sexual harassment, exposure to feminism), (3) gender beliefs (social gender identity, 
gender-egalitarian attitudes, awareness of sexism), (4) feminist-related attitudes and identity (stereotyped views of feminists, private identification as a feminist, public identification as a feminist), (5) finally, two-way interactions between ethnic-minority status and the other variables were included in the last step.

Cognitive appraisal of seeking social support in response to sexism Table 4 summarizes the results from the regression testing for predictors of women's likelihood of seeking social support in response to sexism. Each set of factors added significantly to the model when initially entered. Hence, the last step was selected as the final model, and it accounted for $24 \%$ of the variance. Collinearity statistics were acceptable at this step (minimum tolerance $=.16$ ).

In the final model, there were two significant effects and both were interactions: First, private feminist identification was significant for White European American women $(\beta=.23, t=2.27, p=.03)$ but not for ethnicminority women $(\beta=.08, t=.69, p=.49)$. Similarly, public feminist identification was significant for White European American women $(\beta=.27, t=2.64, p=.01)$ but not for ethnic-minority women $(\beta=-.09, t=-.81, p=.42)$. In summary, the likelihood of seeking social support was more likely among White European American women who identified privately or publicly as feminists.

Cognitive appraisal of confronting sexism The results for the regression with cognitive appraisals of confronting sexism are presented in Table 5. Background factors were not significant in the first step. Gender-related experiences (step 2), gender-related beliefs (step 3), and feminist attitudes and identity (step 4) each added to the model. The interactions entered in step 5, however, did not significantly add to the model. Thus, the final model selected was the fourth step, which accounted for $24 \%$ of the variance. Collinearity statistics were within acceptable ranges (minimum tolerance $=.38$ ).

The following predictors were significant in the final model: social gender identity, stereotyping feminists, and public identification as a feminist. In summary, women were more likely to endorse confronting if they valued their social identity as women, held fewer stereotypes about feminists, and identified publicly as feminists.

\section{Discussion}

Our study builds on prior research pointing to a multidimensional model of feminist identity. We examined factors related to self-identification as a feminist in a sample of ethnically diverse college women. The findings highlight some of the facets that may underlie college women's selfidentification as a feminist as well as how these factors may be related to coping responses to sexism. Prior studies have identified various correlates of either women's feminist identity or their coping. We sought to advance our
Table 4 Standardized betas in hierarchical regression analyses for seeking social support
Ethnic status was dummy coded $(0=$ White European American, $1=$ ethnic minority or mixed ethnicity). Two-way interactions between ethnic-minority status and the other variables were entered in the fifth step. Only significant interaction effects are listed in the table

${ }^{*} p<.05 .{ }^{* *} p<.01 .{ }^{* * *} p<.001$

\begin{tabular}{|c|c|c|c|c|c|}
\hline Variable & $\begin{array}{l}\text { Model } 1 \\
\beta\end{array}$ & $\begin{array}{l}\text { Model } 2 \\
\beta\end{array}$ & $\begin{array}{l}\text { Model } 3 \\
\beta\end{array}$ & $\begin{array}{l}\text { Model } 4 \\
\beta\end{array}$ & $\begin{array}{l}\text { Model } 5 \\
\beta\end{array}$ \\
\hline \multicolumn{6}{|l|}{ 1. BACKGROUND } \\
\hline Parent education & .15 & .10 & .10 & .09 & .13 \\
\hline Ethnic-minority status & $.17^{*}$ & $.18^{*}$ & .14 & .13 & .13 \\
\hline \multicolumn{6}{|l|}{ 2. GENDER-RELATED EXPERIENCES } \\
\hline Sexist events & & .03 & -.09 & -.09 & -.20 \\
\hline Feminist exposure & & $.20^{*}$ & .09 & .12 & -.02 \\
\hline \multicolumn{6}{|l|}{ 3. GENDER-RELATED COGNITIONS } \\
\hline Social gender identity & & & .15 & $.17^{*}$ & .18 \\
\hline Egalitarian attitudes & & & .16 & $.18^{*}$ & .05 \\
\hline Sexism awareness & & & .14 & .15 & .14 \\
\hline \multicolumn{6}{|l|}{ 4. FEMINIST ATTITUDES AND IDENTITY } \\
\hline Feminist stereotyping & & & & .04 & .04 \\
\hline Private feminist & & & & -.01 & .29 \\
\hline Public feminist & & & & -.05 & -.31 \\
\hline \multicolumn{6}{|l|}{ 5. INTERACTIONS } \\
\hline Ethnicity x Private feminist identity & & & & & $-.36^{*}$ \\
\hline Ethnicity x Public feminist identity & & & & & $.35^{*}$ \\
\hline$F_{\text {Model }}$ & $3.48^{*}$ & $3.56^{* *}$ & $4.28^{* * *}$ & $3.05^{* *}$ & $2.69^{* *}$ \\
\hline$R^{2}$ & .04 & .08 & .16 & .16 & .24 \\
\hline$F_{\text {Change }}$ & & $3.54^{*}$ & $4.90^{* *}$ & .31 & $2.04^{*}$ \\
\hline
\end{tabular}


Table 5 Standardized betas in hierarchical regression analyses for confronting
Ethnic status was dummy coded $(0=$ White European American, $1=$ ethnic minority or mixed ethnicity). Two-way interactions between ethnic-minority status and the other variables were entered in the fifth step, but this step did not significantly add to the model, $F(6,150)=1.78$, n.s. ${ }^{*} p<.05$. $^{* *} p<.01 .{ }^{* * *} p<.001$

\begin{tabular}{|c|c|c|c|c|}
\hline Variable & $\begin{array}{l}\text { Model } 1 \\
\beta\end{array}$ & $\begin{array}{l}\text { Model } 2 \\
\beta\end{array}$ & $\begin{array}{l}\text { Model } 3 \\
\beta\end{array}$ & $\begin{array}{l}\text { Model } 4 \\
\beta\end{array}$ \\
\hline \multicolumn{5}{|l|}{ 1. BACKGROUND } \\
\hline Parent education & -.03 & -.09 & -.08 & -.05 \\
\hline Ethnic-minority status & .07 & .10 & .06 & .09 \\
\hline \multicolumn{5}{|c|}{ 2. GENDER-RELATED EXPERIENCES } \\
\hline Sexist events & & .00 & -.09 & -.09 \\
\hline Feminism exposure & & $.30^{* * *}$ & $.20^{*}$ & .11 \\
\hline \multicolumn{5}{|c|}{ 3. GENDER-RELATED COGNITIONS } \\
\hline Social gender identity & & & $.23^{* *}$ & $.17^{*}$ \\
\hline Egalitarian attitudes & & & .12 & .04 \\
\hline Sexism awareness & & & .05 & .04 \\
\hline \multicolumn{5}{|c|}{ 4. FEMINIST ATTITUDES AND IDENTITY } \\
\hline Feminist stereotyping & & & & $-.19^{*}$ \\
\hline Private feminist & & & & .09 \\
\hline Public feminist & & & & $.25^{*}$ \\
\hline$F_{\text {Model }}$ & .57 & $4.21^{* *}$ & $4.50^{* * *}$ & $5.02^{* * *}$ \\
\hline$R^{2}$ & .01 & .09 & .16 & .24 \\
\hline$F_{\text {Change }}$ & & $7.81^{* *}$ & $4.53^{* *}$ & $5.37^{* *}$ \\
\hline
\end{tabular}

understanding by testing the independent contributions of theoretically relevant predictors using hierarchical regression. In the bivariate correlations, nearly every measure was significantly correlated with self-identification as a feminist. Once predictors were considered simultaneously in the regression analyses, however, a smaller set of factors were implicated (cf. Tables 1 vs. 3). Also, feminist identity significantly predicted women's cognitive appraisals of proactive coping to sexual harassment. These analyses suggest some of the facets that independently underlie feminist identity and offer implications for women's responses to sexism.

\section{Women's Self-Identification as a Feminist: Toward} a Multidimensional Model

Our multidimensional model of feminist identity was comprised of three components: (1) experiences with sexism and feminism (sexist events, exposure to feminism), (2) gender-related beliefs (social gender identity, egalitarian attitudes, and sexism awareness), and (3) stereotyped evaluations of feminists. Each of the three hypothesized components independently contributed to women's feminist self-identification. However, not all of the specific factors were significant. Thus, the model highlighted the relative strength of some factors over others in predicting feminist identification. We review each of these components below. Before discussing the significance of the three components, we first address whether women's sociocultural backgrounds affected our results.

\section{Sociocultural Backgrounds}

Researchers have emphasized the need to take into account individuals' ethnic and socioeconomic backgrounds when formulating models of feminist identity (e.g., Boisnier 2003; Henley et al. 1998; Moradi et al. 2002; Robnett et al. 2011). Accordingly, we tested whether ethnic-minority status (controlling for parents' education) moderated any of the hypothesized effects on feminist self-identification. This was not indicated in the present study. Nonetheless, as discussed later, relations between women's sociocultural backgrounds and feminist identification deserve further attention in future research.

\section{Gender-Related Life Experiences}

Reported experiences with sexism and learning about feminism are two gender-related life experience that we hypothesized would contribute to women's selfidentification as feminists. In different ways, these experiences may increase the relevance of feminism in women's lives. As expected, experiences with sexism and exposure to feminism each significantly predicted self-identification as a feminist when initially entered into the regression model. However, only exposure to feminism remained significant in the final model. Perhaps exposure to feminism was the more robust factor because it is possible for a woman to identify as a feminist even if she has not experienced much sexism. In contrast, learning about feminism is a necessary life experience for identifying as a feminist. Exposure to feminism also may help to dispel 
some of the negative stereotypes about feminists (e.g., Nelson et al. 2008).

Although experiences with sexism did not emerge as a significant factor in the final model, it may have an indirect influence that was not detected in the present analyses. For example, Nelson et al. (2008) found that experiences with sexism indirectly influenced women's feminist selfidentification by increasing their commitment to genderegalitarian beliefs. In addition, age level and student status may moderate the relation between sexist experiences and feminist identification. Experiences with sexism may have a stronger effect on feminist identity among older women who have encountered more sexist acts in work settings.

\section{Gender-Related Beliefs}

Social gender identity, gender-egalitarian attitudes, and awareness of societal sexism were three facets of genderrelated beliefs hypothesized to predict women's selfidentification as a feminist. All three variables were associated with feminist identity in the bivariate correlations; however, only social gender identity and gender-egalitarian attitudes were retained in the final regression model. Thus, awareness of societal sexism was not as robust as the other facets of the beliefs component of feminist identity. Gender-egalitarian attitudes may account for any variance otherwise associated with awareness of sexism.

Gender-related beliefs establish the ideological basis for a woman to become a feminist. Although these factors may be necessary components, our model indicates that they are not sufficient conditions to establish a feminist identity. As discussed next, some women who hold the ideological beliefs to be a feminist nonetheless may balk at identifying as a feminist due to lingering negative stereotypes about what it means to be a feminist.

\section{Stereotyped Evaluations of Feminists}

After controlling for the experience with sexism and the beliefs and knowledge components in our model, stereotyped evaluations continued to add significantly to the prediction of women's self-identifications as a feminist. Our findings therefore strongly suggest that holding stereotyped views of feminists may be a key factor that accounts for the "I'm not a feminist but" phenomenon. This notion is consistent with theory and research on group belonging. Deciding to publicly join a group requires having an initially positive (or at least neutral) view of the group. Also, once one adopts a social identity, positive evaluation of the group will further increase (Deaux et al. 1999; Tajfel 1982; Turner 2000). Conversely, holding negative stereotypes about a group - such as feminists - will lead women to avoid embracing it in their identity.
Prior research has shown that one of the most common negative stereotypes about feminists is that they are unfeminine or sexually unattractive. These views may impede young heterosexual women's willingness to identify as a feminist (Rudman and Fairchild 2007; Unger et al. 1982). Indeed, our exploratory follow-up analyses highlighted the stereotypes of feminists as "undesirable" (vs. "desirable"), "plain" (vs. "sexy"), or "gay" (vs. "straight") as the strongest impediments to women's willingness to consider themselves feminists. Not only may these particular stereotypes dissuade many women from identifying as feminists, they can affect feminists' own ingroup biases. For example, in one study, self-identified feminists were more likely to agree with a traditionally feminine-appearing speaker communicating a pro-feminist message than a less feminine-appearing speaker communicating the same message (Bullock and Fernald 2003). Thus, even feminists may be susceptible to an implicit prejudice that being a feminist is incompatible with heterosexual attractiveness.

In earlier generations, many women hid their competence (i.e., "playing dumb") to appear more attractive to men (e.g., Sherman 1983). Perhaps for similar reasons some contemporary women with feminist values avoid publicly labeling themselves as "feminists." Unfortunately, the risk of peer rejection has often led girls and women away from considering identities and activities that might be empowering as well as consistent with their values and interests (see Leaper and Friedman 2007, for a review). Given the pervasive slandering of feminism in the media (see Anderson 2010), many girls and women may formulate distorted notions of what it means to be a feminist (e.g., Houvouras and Carter 2008; Manago et al. 2009).

Since conducting our investigation, Nelson et al. (2008) published a noteworthy study of women's feminist identity. These researchers similarly found that experienced sexist events, exposure to feminism (taking women's studies classes or having a feminist mother), gender-egalitarian attitudes, and stereotyped evaluations of feminists were each directly or indirectly related to women's feminist selfidentification. In a structural equation model, stereotyped evaluations of feminists and gender attitudes were directly linked to feminist self-identification. Furthermore, exposure to feminism and experienced sexist events had indirect influences via their associations with gender attitudes. Thus, both Nelson et al.'s study and the present investigation lend support to the notion that stereotyped evaluations of feminists may play a critical role in women's willingness to self-identify as a feminist after controlling for other relevant factors such as attitudes and prior experiences.

Whereas the two studies overlap, we considered some factors that were not included in Nelson et al.'s (2008) study. First, we examined the possible relation of women's 
social gender identity in relation to their feminist identity. Second, we measured women's awareness of sexism in addition to women's gender-egalitarian beliefs. Third, we took into account participants' ethnic backgrounds and parent education (as a proxy for SES). Finally, as discussed next, we investigated women's feminist identity in relation to their reported coping responses to sexual harassment (whereas Nelson et al. looked at reported collective action).

\section{Women's Responses to Sexism}

In the second part of our study, we considered facets of women's feminist identity in relation to their coping responses to sexual harassment. The components that we investigated included women's experience with sexism and feminism, gender-related beliefs, stereotyped views of feminists, and their private identification and public identifications as feminists. As explained below, somewhat different patterns of results were obtained for cognitive appraisals of seeking support and confronting.

\section{Cognitive Appraisals of Seeking Social Support}

Both private feminist identity and public feminist identity were positively related to seeking support in response to sexism; however, these factors predicted seeking support only among White European American women. Preliminary analyses indicated that ethnic-minority women were more likely than White European American to seek support in response to sexism. To the extent that ethnic-minority women may experience more forms of overall discrimination (i.e., racial/ethnic and gender discrimination), perhaps they have more experience seeking support when it occurs. In contrast, because White European American women are not likely to experience racial/ethnic discrimination, gender discrimination may tend to be more salient for White European American women than ethnic-minority women (Levin et al. 2002; Turner and Brown 2007); in turn, identifying as a feminist may help White European American women recognize gender discrimination and subsequently look to others for help.

\section{Cognitive Appraisals of Confronting Sexism}

Women were more likely to have positive appraisals of confronting sexual harassment if they identified more strongly as women (social gender identity), did not stereotype feminists, and publicly identified as a feminist. Identifying with other women may add to women's belief that confronting will benefit both themselves and women as a whole (Ayres et al. 2009). It is notable that public - but not privateidentification was a significant factor in our analysis. The former may reflect a stronger commitment to a feminist identity than the latter (Zucker 2004). Accordingly, a woman's willingness to publicly express her identity as a feminist may help to strengthen her belief in the efficacy of confronting discrimination. Having a feminist identity is also related to holding a set of beliefs that may lead women to consider confronting sexism as "the right thing to do." Compatible with cognitive consistency theory (McGuire 2000), beliefs and actions are conjoined when feministidentified women endorse confronting sexist acts.

Public self-identification as a feminist predicted confronting regardless of the women's ethnic background, and it predicted seeking support (but only for White European American women). Confronting a perpetrator is a highly public form of coping; in comparison, seeking support is more private. Publicly identifying a feminist identity, therefore, may help to strengthen all women's resolve to challenge sexist behavior when it occurs. However, having a feminist identity does not (and should not) necessarily lead to confrontation. Confronting a perpetrator of sexual harassment carries the risk of potential threats ranging from negative emotion to physical harm. Hence, the costs and benefits of confronting must be weighed depending on the situation (Kaiser and Miller 2004; Shelton and Stewart 2004). In some instances, the most effective coping may involve seeking support from an authority figure, friend, partner, or family member.

\section{Limitations, Future Directions, and Conclusion}

We close by noting some limitations of our study and suggest some directions for future research. First, our study was based on a convenience sample of predominantly heterosexual women who attended a socially progressive university. The life experiences of our participants may not generalize to women from different backgrounds, sexual orientations, ages, or social contexts. Although we considered women's ethnicminority status as a moderator, we were not able to compare different ethnic-minority groups. Pathways to feminist identity may vary for women depending on particular ethnic backgrounds (e.g., Harnois 2005; Robnett et al. 2011) or sexual orientations (e.g., Friedman and Leaper 2010; Szymanski 2004). Furthermore, as in most prior studies of feminist identity, our sample did not include any men. There may be greater coherence among the components of feminist identity in women than men (McCabe 2005). Thus, in future research, it will be helpful to consider in more depth how various individual characteristics, such as gender, sexual orientation, ethnicity, and socioeconomic status, may moderate factors related to feminist identity.

Second, we did not distinguish between different types of feminism in women's self-identifications. Feminism is a complex construct that involves multiple definitions and 
corresponding identities (see Aronson 2003; Henley et al. 1998). The kinds of factors that lead women to identify as radical feminists, liberal feminists, cultural feminists, or womanists may vary (e.g., Boisnier 2003; Nelson et al. 2008; Robnett et al. 2011). This point is also pertinent when considering the intersection between gender and race/ethnicity because many women of color may be more likely to identify as womanists and to disidentify as feminists (Aronson 2003; Harnois 2005; Myaskovsky and Wittig 1997).

A third limitation is that all of our measures were based on women's self reports, which are subject to possible biases. For example, women often underestimate the incidence of personally experienced discrimination (Crosby 1984; Taylor et al. 1990). Also, we do not know how well the women's reported responses to sexism might correspond to their actual behavior. For example, it is likely that women are more likely to consider confronting someone for sexism than to actually do this (Hyers 2007). Nonetheless, our assessments reflected women's cognitive appraisals, which are known to affect coping behavior (Kaiser and Miller 2004; Lazarus 1999). We encourage researchers to examine how these cognitive appraisals are related to actual behaviors in future studies.

Finally, we only considered confronting perpetrators and seeking social support as possible responses to hypothetical instances of sexual harassment. Other proactive responses include forms of collective action such as working for legal or policy changes (e.g., Friedman and Leaper 2010; Liss et al. 2004; Nelson et al. 2008). In addition, it is worth recognizing that the likelihood of using particular coping strategies may vary depending on the particular context of the sexist event (e.g., see Ayres et al. 2009; Cortina and Wasti 2005). In future research, we suggest examining how feminist identity may affect a greater variety of coping responses in a variety of settings.

In conclusion, our study built on prior investigations into the correlates of women's social identity as a feminist. In our first set of analyses, we identified a set of predictors that independently accounted for variability in women's selfidentification as feminists. Our multi-dimensional model emphasized the possible influences of experiences with sexism and feminism, gender-related beliefs, and stereotyped evaluations of feminists. The latter factor partly explains the "I'm not a feminist but" phenomenon whereby some women endorse gender-egalitarian views but do not identify as feminists (Buschman and Lenart 1996; Roy et al. 2007; Williams and Wittig 1997; Zucker 2004). In our second set of analyses, we highlighted possible implications of these facets of feminist identity for women's coping with sexism. Women who publicly identified as feminist were more likely to offer a positive appraisal of confronting sexist acts. Thus, in this manner, a feminist identity may act as a buffer against the stresses of gender discrimination.
Acknowledgements The research was supported by grants to Campbell Leaper from the Academic Senate and Division of Social Sciences of the University of California, Santa Cruz. Melanie Ayres, Carly Friedman, and Rachael Robnett are thanked for thoughtful comments on earlier drafts. Preliminary findings from this study were previously presented at the 2007 Conference of the American Psychological Association, San Francisco.

Open Access This article is distributed under the terms of the Creative Commons Attribution Noncommercial License which permits any noncommercial use, distribution, and reproduction in any medium, provided the original author(s) and source are credited.

\section{References}

American Association of University of Women. (2001). Hostile hallways: Bullying, teasing, and sexual harassment in school. Washington, DC: Association of University Women.

Anderson, K. J. (2010). Benign bigotry: The psychology of subtle prejudice. New York: Cambridge University Press.

Aronson, P. (2003). Feminists or "postfeminists"? Young women's attitudes toward feminism and gender relations. Gender \& Society, 17, 903-922.

Ayres, M. M., Friedman, C. K., \& Leaper, C. (2009). Individual and situational factors related to young women's likelihood of confronting sexism in their everyday lives. Sex Roles, 61, 449-460.

Bargad, A., \& Hyde, J. S. (1991). Women's studies: A study of feminist identity development in women. Psychology of Women Quarterly, 15, 181-201.

Berryman-Fink, C., \& Verderber, K. S. (1985). Attributions of the term feminist: A factor analytic development of a measuring instrument. Psychology of Women Quarterly, 9, 51-64.

Boisnier, A. D. (2003). Race and women's identity development: Distinguishing between feminism and womanism among Black and White women. Sex Roles, 49, 211-218.

Bullock, H. E., \& Fernald, J. L. (2003). "Feminism lite?" Feminist identification, speaker, appearance, and perceptions of feminist and antifeminist messengers. Psychology of Women Quarterly, 27, 291-299.

Burn, S. M., Aboud, R., \& Moyles, C. (2000). The relationship between gender social identity and support for feminism. Sex Roles, 42, 1081-1089.

Buschman, J. K., \& Lenart, S. (1996). "I am not a feminist, but...": College women, feminism, and negative experiences. Political Psychology, 17, 59-75.

Chen, X., Ender, P., Mitchell, M. \& Wells, C. (2003). Regression with SPSS. Retrieved from http://www.ats.ucla.edu/stat/spss/webbooks/ reg/default.htm.

Cole, E. R. (2009). Intersectionality and research in psychology. American Psychologist, 64, 170-180.

Cortina, L. M., \& Wasti, S. A. (2005). Profiles in coping: Responses to sexual harassment across persons, organizations, and cultures. Journal of Applied Psychology, 90, 182-192.

Cowan, G., Mestlin, M., \& Masek, J. (1992). Predictors of feminist self-labeling. Sex Roles, 27, 321-330.

Crosby, F. (1984). The denial of personal discrimination. American Behavioral Scientist, 27, 371-386.

Deaux, K., Reid, A., Mizrahi, K., \& Cotting, D. (1999). Connecting the person to the social: The functions of social identification. Mahwah: Lawrence Erlbaum Associates Publishers.

Dodd, E. H., Giuliano, T. A., Boutell, J. M., \& Moran, B. E. (2001). Respected or rejected: Perceptions of women who confront sexist remarks. Sex Roles, 45, 567. 
Downing, N., \& Roush, K. (1985). From passive acceptance to active commitment: A model of feminist identity development for women. Counseling Psychologist, 13, 695-709.

Egan, S. K., \& Perry, D. G. (2001). Gender identity: A multidimensional analysis with implications for psychosocial development. Developmental Psychology, 37, 451-463.

Eisele, H., \& Stake, J. (2008). The differential relationship of feminist attitudes and feminist identity to self-efficacy. Psychology of Women Quarterly, 32, 233-244.

Ex, C. T., \& Janssens, J. M. (1998). Maternal influences on daughters' gender role attitudes. Sex Roles, 38, 171-186.

Finkelstein, D. M., Kubzansky, L. D., Capitman, J., \& Goodman, E. (2007). Socioeconomic differences in adolescent stress: The role of psychological resources. Journal of Adolescent Health, 40, $127-134$.

Fischer, A. R., Tokar, D. M., Mergl, M. M., Good, G. E., Hill, M. S., \& Blum, S. A. (2000). Assessing women's feminist identity development: Studies of convergent, discriminant, and structural validity. Psychology of Women Quarterly, 24, 15-29.

Foster, M. D. (2000). Positive and negative responses to personal discrimination: Does coping make a difference? The Journal of Social Psychology, 140, 93-106.

Friedman, C., \& Leaper, C. (2010). Sexual-minority college women's experiences with discrimination: Relations with identity and collective action. Psychology of Women Quarterly, 34, 152-164.

Galambos, N. L., Petersen, A. C., Richards, M., \& Gitelson, I. B. (1985). The attitudes toward women scale for adolescents (AWSA): A study of reliability and validity. Sex Roles, 13, 343-356.

Harnois, C. E. (2005). Different paths to different feminisms? Bridging multiracial feminist theory and quantitative sociological gender research. Gender \& Society, 19, 809-829.

Henderson-King, D. H., \& Stewart, A. J. (1994). Women or feminists? Assessing women's group consciousness. Sex Roles, 31, 505-516.

Henderson-King, D. H., \& Stewart, A. J. (1997). Feminist consciousness: Perspectives on women's experience. Personality and Social Psychology Bulletin, 23, 415-426.

Henderson-King, D. H., \& Stewart, A. J. (1999). Educational experiences and shifts ingroup consciousness: Studying women. Personality and Social Psychology Bulletin, 25, 390-399.

Henderson-King, D. H., \& Zhermer, N. (2003). Feminist consciousness among Russians and Americans. Sex Roles, 48, 143-155.

Henley, N. M., Meng, K., O’Brien, D., McCarthy, W. J., \& Sockloskie, R. J. (1998). Developing a scale to measure the diversity of feminist attitudes. Psychology of Women Quarterly, $22,317-348$

Houvouras, S., \& Carter, J. S. (2008). The F word: College students' definitions of a feminist. Sociological Forum, 23, 234-256.

Hyde, J. S. (2002). Feminist identity development: The current stage of theory, research, and practice. Counseling Psychologist, 30, $105-110$.

Hyers, L. L. (2007). Resisting prejudice every day: Exploring women's assertive responses to anti-Black racism, antiSemitism, heterosexism, and sexism. Sex Roles, 56, 1-12.

Jackson, L. A., Fleury, R. E., \& Lewandowski, D. A. (1996). Feminism: Definitions, support, and correlates of support among female and male college students. Sex Roles, 34, 687-693.

Jagger, A. (1983). Feminist politics and human nature. Totowa: Rowman \& Allenheid.

Jaschik-Herman, M. L., \& Fisk, A. (1995). Women's perceptions and labeling of sexual harassment in academia before and after the Hill-Thomas hearings. Sex Roles, 33, 439-446.

Kaiser, C. R., \& Miller, C. T. (2004). A stress and coping perspective on confronting sexism. Psychology of Women Quarterly, 28, $168-178$.

Klonoff, E. A., \& Landrine, H. (1995). The schedule of sexist events: A measure of lifetime and recent sexist discrimination in women's lives. Psychology of Women Quarterly, 19, 439472.

Klonoff, E. A., Landrine, H., \& Scott, J. (1995). Double jeopardy: Ethnicity and gender in health research. In H. Landrine (Ed.), Bringing cultural diversity to feminist psychology (pp. 335-360). Washington, DC: American Psychological Association.

Lazarus, R. S. (1999). Stress and emotion: A new synthesis. New York: Springer.

Lazarus, R. S., \& Folkman, S. (1984). Stress, appraisal, and coping. New York: Springer.

Leaper, C., \& Brown, C. S. (2008). Perceived experiences with sexism among adolescent girls. Child Development, 79, 685-704.

Leaper, C., \& Friedman, C. K. (2007). The socialization of gender. In J. E. Grusec \& P. D. Hastings (Eds.), Handbook of socialization: Theory and research (pp. 561-587). New York: Guilford.

Leaper, C., \& Robnett, R. D. (2011). Sexism. In R. J. R. Levesque (Ed.), Encyclopedia of adolescence. New York: Springer.

Levin, S., Sinclair, S., Veniegas, R. C., \& Taylor, P. L. (2002). Perceived discrimination in the context of multiple group memberships. Psychological Science, 13, 557-560.

Limbaugh, R. (2005, August 12). The rush Limbaugh show [Radio show]. Retrieved from, http://mediamatters.org/mmtv/ 200508160001.

Liss, M., \& Erchull, M. J. (2010). Everyone feels empowered: Understanding feminist self-labeling. Psychology of Women Quarterly, 34, 85-96.

Liss, M., O'Connor, C., Morosky, E., \& Crawford, M. (2001). What makes a feminist? Predictors and correlates of feminist social identity in college women. Psychology of Women Quarterly, 25, 124-133.

Liss, M., Crawford, M., \& Popp, D. (2004). Predictors and correlates of collective action. Sex Roles, 50, 771-779.

Lopez, K. J. (2005, December 29). Interrogatory: Q \& A with Kate O'Beirne. National Review Online. Retrieved from http://old. nationalreview.com/interrogatory/obeirne200512290819.asp.

Luhtanen, R., \& Crocker, J. (1992). A collective self-esteem scale: Self-evaluation of one's social identity. Personality \& Social Psychology Bulletin, 18, 302-318.

Manago, A. M., Brown, C. S., \& Leaper, C. (2009). Feminist identity among Latina adolescents. Journal of Adolescent Research, 24, $750-756$.

Marcia, J. E. (1980). Identity in adolescence. In J. Adelson (Ed.), Handbook of adolescent psychology (pp. 159-197). New York: Wiley.

McCabe, J. (2005). What's in a label? The relationship between feminist self-identification and "feminist" attitudes among U.S. women and men. Gender \& Society, 19, 480-505.

McGuire, W. J. (2000). Cognitive consistency theories. In A. E. Kazdin (Ed.), Encyclopedia of psychology (Vol. 2, pp. 139-140). Washington, DC: American Psychological Association.

Moradi, B., \& Subich, L. M. (2002). Feminist identity development measures: Comparing the psychometrics of three instruments. Counseling Psychologist, 30, 66-86.

Moradi, B., Subich, L. M., \& Phillips, J. C. (2002). Revisiting feminist identity development theory, research and practice. Counseling Psychologist, 30, 6-43.

Morgan, B. L. (1996). Putting the feminism into feminism scales: Introduction of a Liberal Feminist Attitude and Ideology Scale (LFAIS). Sex Roles, 34, 359-390.

Myaskovsky, L., \& Wittig, M. A. (1997). Predictors of feminist social identity among college women. Sex Roles, 37, 861-883.

Nelson, J. A., Liss, M., Erchull, M. J., Hurt, M. M., Ramsey, L. R., Turner, D. L., et al. (2008). Identity in action: Predictors of feminist self-identification and collective action. Sex Roles, 58, 721-728. 
O'Beirne, K. (2006). Women who make the world worse: And how their radical feminist assault is ruining our schools, families, military, and sports. New York: Sentinel.

Park, C. L., \& Folkman, S. (1997). Meaning in the context of stress and coping. Review of General Psychology, 1, 115-144.

Reid, P. T., \& Comas-Diaz, L. (1990). Gender and ethnicity: Perspectives on dual status. Sex Roles, 22, 397-408.

Reid, A., \& Purcell, N. (2004). Pathways to feminist identification. Sex Roles, 50, 759-769.

Robnett, R. D., Anderson, K. J. \& Hunter, L. E. (2011, March). Predictors of attitudes toward feminism: An examination of ethnicity-specific pathways. Presentation at the Annual Meeting of the Association for Women in Psychology, Philadelphia, PA.

Rosell, M. C., \& Hartman, S. L. (2004). Self-presentation of beliefs about gender discrimination and feminism. Sex Roles, 44, 647659.

Roy, R. E., Weibust, K. S., \& Miller, C. T. (2007). Effects of stereotypes about feminists on feminist self-identification. Psychology of Women Quarterly, 31, 146-156.

Rudman, L. A., \& Fairchild, K. (2007). The F word: Is feminism incompatible with beauty and romance? Psychology of Women Quarterly, 31, 125-136.

Shelton, J. N., \& Stewart, R. E. (2004). Confronting perpetrators of prejudice: The inhibitory effects of social costs. Psychology of Women Quarterly, 28, 215-223.

Sherman, J. (1983). Girls talk about mathematics and their future: A partial replication. Psychology of Women Quarterly, 7, 338342.

Smith, C. A. (1999). I enjoy being a girl: Collective self-esteem, feminism, and attitudes toward women. Sex Roles, 40, 281-293.

Spence, J. T. (1993). Gender-related traits and gender ideology: Evidence for a multifactorial theory. Journal of Personality and Social Psychology, 64, 624-635.
Swim, J. K., \& Hyers, L. L. (1999). Excuse me-what did you just say?!: Women's public and private responses to sexist remarks. Journal of Experimental Social Psychology, 35, 68-88.

Swim, J. K., Aikin, K. J., Hall, W. S., \& Hunter, B. A. (1995). Sexism and racism: Old fashioned and modern prejudices. Journal of Personality and Social Psychology, 68, 199-214.

Szymanski, D. M. (2004). Relations among dimensions of feminist and internalized heterosexism in lesbians and bisexual women. Sex Roles, 51, 145-159.

Tajfel, H. (1982). Social psychology of intergroup relations. Annual Review of Psychology, 33, 1-39.

Taylor, D. M., Wright, S. C., Moghaddam, F. M., \& Lalonde, R. N. (1990). The personal/group discrimination discrepancy: Perceiving my group, but not my self, to be a target for discrimination. Personality and Social Psychology Bulletin, 16, 254-262.

Turner, J. C. (2000). Social identity. In A. E. Kazdin (Ed.), Encyclopedia of psychology (Vol. 7, pp. 341-343). Washington, DC: American Psychological Association.

Turner, K. L., \& Brown, C. S. (2007). The centrality of gender and ethnic identities across individuals and contexts. Social Development, 16, 700-719.

Unger, R. K., Hilderbrand, M., \& Madar, T. (1982). Physical attractiveness and assumptions about social deviance: Some sex by sex comparisons. Personality \& Social Psychology Bulletin, 8 , 293-301.

U. S. Census Bureau. (2008). Selected characteristics of people at specified levels of poverty in the past 12 months. Retrieved from http://factfinder.census.gov.

Williams, R., \& Wittig, M. A. (1997). "I'm not a feminist, but...": Factors contributing to the discrepancy between pro-feminist orientation and feminist social identity. Sex Roles, 37, 885-904.

Zucker, A. N. (2004). Disavowing social identities: What it means when women say, "I'm not a feminist, but...". Psychology of Women Quarterly, 28, 423-435. 